\title{
A Case Report of Pregnant Lady having COVID-19 Delivered via Cesarean Section in Tertiary Care Hospital in Pakistan
}

\author{
Shahida Husain $\operatorname{Tarar}^{1}$ (D), Hamna Atta² ${ }^{\text {(D) }}$, Marina Khalid ${ }^{1}$, Sadaf Saeed ${ }^{1}$, \\ Syed Muhammad Ali Shah ${ }^{1}$ D , Komal Rizwan ${ }^{3 *}(\mathbb{D})$, Tahir Rasheed ${ }^{4}$ (D) and \\ Muhammad Bilal ${ }^{5}$
}

\begin{abstract}
${ }^{1}$ Aziz Bhatti Shaheed Teaching Hospital Gujrat, Gujrat - 50700, Pakistan. ${ }^{2}$ District Head Quarter Hospital Rawalpindi, Pakistan. ${ }^{3}$ Department of Chemistry, University of Sahiwal, Sahiwal - 57000, Pakistan. ${ }^{4}$ School of Chemistry and Chemical Engineering, Shanghai Jiao Tong University, Shanghai - 200240, China. ${ }^{5}$ School of Life Science and Food Engineering, Huaiyin Institute of Technology, Huaian - 223003, China.
\end{abstract}

\begin{abstract}
This is case report of $\mathbf{4 0}$ years female who presented at term and was co-infected with COVID-19. She had history of previous $3 \mathrm{C}$-sections so another C-section was performed due to fear of uterine rupture. Her surgery went uneventful. She recovered after surgery from COVID-19. Her infant also tested negative for COVID-19.

Keywords: COVID-19, Tertiary Care Hospital
\end{abstract}

*Correspondence: Komal.rizwan45@yahoo.com

(Received: April 19, 2020; accepted: April 25, 2020)

Citation: Tarar SH, Atta H, Khalid M, et al. A Case Report of Pregnant Lady having COVID-19 Delivered via Cesarean Section in Tertiary Care Hospital in Pakistan. J Pure Appl Microbiol. 2020;14(2):1121-1123. doi: 10.22207/JPAM.14.2.06

(c) The Author(s) 2020. Open Access. This article is distributed under the terms of the Creative Commons Attribution 4.0 International License which permits unrestricted use, sharing, distribution, and reproduction in any medium, provided you give appropriate credit to the original author(s) and the source, provide a link to the Creative Commons license, and indicate if changes were made. 


\section{INTRODUCTION}

The epidemic of COVID-19 has spread from Wuhan, a city of China to almost every part of the world from December 2019 ${ }^{1}$. More than 2.2 million people have been affected globally with this pandemic as of today ${ }^{2}$. There is evidence of the spread of the virus from person to person in close contacts and till now, there has been no treatment or vaccine that has been found effective ${ }^{3-5}$. Past studies have shown that pregnant females are more at risk of contacting a viral infection and are associated with poor outcomes such as stillbirth, preterm delivery, spontaneous abortion, or maternal death ${ }^{6-9}$. There is limited clinical data regarding outcomes of pregnant females who have COVID-19 during the pregnancy. In this case report, we report a case of a 40-year-old pregnant female who was 39 weeks pregnant and underwent a cesarean section for delivery of a healthy infant.

\section{Case Report}

A 40-year-old female who was $\mathrm{G}_{4} \mathrm{P}_{3} \mathrm{~A}_{0}$ with a history of previous 3 lower segment C-sections, having gestation of 39 weeks and expected date of delivery on $17^{\text {th }}$ April 2020. She presented in outdoor of Aziz Bhatti Shaheed Teaching Hospital Gujrat with complaints of cough and breathlessness for the last 1 day on $12^{\text {th }}$ April 2020. She had a history of contact with diagnosed COVID-19 patients on $6^{\text {th }}$ April 2020. She was admitted in isolation of hospital as a suspected case of COVID-19 and RT-PCR of the nasopharyngeal swab was sent which came back positive for COVID-19. Her physical examination revealed that she had a pulse of 97 beats/min, a respiratory rate of 22 breaths/min, a temperature of $98.6^{\circ} \mathrm{F}$ and blood pressure was $110 / 70 \mathrm{mmHg}$. She had bilateral fine crepitations at lung bases however rest of the examination was normal. Further investigations showed that she was anemic having $\mathrm{Hb} 7.0 \mathrm{~g} / \mathrm{dl}$, total leukocyte count $5500 / \mathrm{mm}^{3}$; on a differential count, she had a neutrophil count of $84 \%$ and lymphocytes count of $12 \%$ and her platelet count was $199000 / \mathrm{mm}^{3}$. She was negative for HBsAg, Anti-HCV-Ab, and HIV. She had a normal liver, renal function tests, PT, APTT, and serum electrolytes. Her ECG, chest $X$-ray, and fetal ultrasound were also in normal limits. She was transfused two pints of packed cell volumes. Her anesthesia fitness was taken and C-section was performed due to a high risk of rupture as she had three previous cesarean sections. Her surgery went uneventful, which was performed under spinal anesthesia and the patient recovered without any complications. The infant was shifted to isolation in the pediatric nursery and a nasopharyngeal swab was sent for RT-PCR of COVID-19, which came back negative. The patient is still admitted in isolation and recovering well.

\section{DISCUSSION}

SARS-CoV-2 is a novel coronavirus that has been declared as a pandemic by WHO. It has spread from China to almost all countries of the world. The main routes of transmission include respiratory droplets as well as through contact ${ }^{3}$. Multiple studies have determined that respiratory viruses have poor outcomes and are associated with complications during delivery due to changes in immune responses in a pregnant female ${ }^{6-10}$. In one case series of ten pregnant patients infected with SARS in Hong Kong ${ }^{11}$, it was associated with multiple complications including spontaneous abortion, preterm delivery, and/or maternal death. One recent case report of a pregnant patient with COVID-19 showed that it was not associated with any complications during delivery. However, normal vaginal delivery was performed in their case compared to C-section in this case ${ }^{12}$. One recent review of 32 pregnant patients with COVID-19 determined that about $47 \%$ of patients had preterm delivery and $6.25 \%$ ( 2 patients) were needed intensive care ${ }^{13}$. Another review stated that mother to child transmission of SARS-CoV-2 is low in patients delivered via cesarean deliver $y^{14}$.

This case reported a pregnant female who was affected with COVID-19 and delivered via C-section at 39 weeks of gestation. A healthy infant was born who was not affected by COVID-19 after testing. The postpartum and neonatal course was without any event. All the healthcare workers remained asymptomatic. Although the patient had previous three cesarean sections, still her surgery was without any complicated event. This may be attributed to that patient was healthy and was on regular visits to the hospital before delivery and her fetus remained healthy throughout the pregnancy. Patients had no previous medical illness and her COVID-19 was mild. Thus making this an uncomplicated delivery and infant was free of COVID-19 as the vertical transmission is low ${ }^{14}$. 
COVID-19 is a new challenge for this year. There is not enough data regarding the outcomes of pregnancy in COVID-19 positive pregnant mothers. This is probably the first case report in Pakistan regarding the delivery of COVID-19 patients via cesarean section. Further studies/case series/ case reports are needed to be performed in this regard so that the exact nature of outcomes can be established.

\section{ACKNOWLEDGMENTS}

All listed author(s) are thankful to their representative universities/institutes for providing the related support to compile this work.

\section{CONFLICT OF INTEREST}

The authors declare that there is no conflict of interest.

\section{AUTHORS' CONTRIBUTION}

All listed author(s) have made a substantial, direct and intellectual contribution to the work, and approved it for publication.

\section{FUNDING}

None.

\section{ETHICS STATEMENT}

This is a case report of a patient which is just observation of event and was reported after the informed consent of patient and approval of ethical committee of hospital. No intervention other than standard treatment was done.

\section{DATA AVAILABILITY}

Not applicable.

\section{REFERENCES}

1. Zhu N, Zhang D, Wang W, et al. A Novel Coronavirus from Patients with Pneumonia in China, 2019. N Engl J Med. 2020.

2. World Health Organization official website; https:// www.who.int
3. Jin $\mathrm{YH}, \mathrm{Cai} \mathrm{L}$, Cheng ZS, et al. A rapid advice guideline for the diagnosis and treatment of 2019 novel coronavirus (2019-nCoV) infected pneumonia (standard version). Mil Med Res. 2020;7(1):4. https://doi.org/10.1186/ s40779-020-0233-6

4. Li Q, Guan X, Wu P, et al. Early Transmission Dynamics in Wuhan, China, of Novel Coronavirus-Infected Pneumonia. N Engl J Med. 2020.

5. Wang D, Hu B, Hu C, et al. Clinical Characteristics of 138 Hospitalized Patients With 2019 Novel CoronavirusInfected Pneumonia in Wuhan, China. JAMA. 2020. https://doi.org/10.1001/jama.2020.1585

6. Wong SF, Chow KM, Leung TN, et al. Pregnancy and perinatal outcomes of women with severe acute respiratory syndrome. Am J Obstet Gynecol. 2004;191(1):292-297. https://doi.org/10.1016/j. ajog.2003.11.019

7. Creanga AA, Johnson TF, Graitcer SB, et al. Severity of 2009 pandemic influenza A (H1N1) virus infection in pregnant women. Obstet Gynecol. 2010;115(4):717-726. https://doi.org/10.1097/ AOG.0b013e3181d57947

8. Alserehi H, Wali G, Alshukairi A, Alraddadi B. Impact of Middle East Respiratory Syndrome coronavirus (MERS-CoV) on pregnancy and perinatal outcome. BMC Infect Dis. 2016;16:105. https://doi.org/10.1186/ s12879-016-1437-y

9. Olgun NS. Viral Infections in Pregnancy: A Focus on Ebola Virus. Curr Pharm Des. 2018;24(9): 993-998. https://doi.org/10.2174/1381612824666180130121 946

10. Warning JC, McCracken SA, Morris JM. A balancing act: mechanisms by which the fetus avoids rejection by the maternal immune system. Reproduction. 2011;141(6):715-724. https://doi.org/10.1530/REP10-0360

11. Wong SF, Chow KM, de Swiet M. Severe Acute Respiratory Syndrome and pregnancy. BJOG. 2003;110(7):641-642. https://doi.org/10.1046/j.14710528.2003.03008.x

12. Wang $X$, Zhou Z, Jianping Z, Zhu F, Tang $Y$, Shen $X$. A case of 2019 Novel Coronavirus in a pregnant woman with preterm delivery. Clin Infect Dis. 2020. https:// doi.org/10.1093/cid/ciaa200

13. E. Mullins, D. Evans, R.M. Viner, P. O’Brien, E. Morris Coronavirus in pregnancy and delivery: rapid review and expert consensus. medRxiv. 2020. https://doi. org/10.1101/2020.03.06.20032144

14. Parazzini F, Bortolus R, Mauri PA, Favilli A, Gerli S, Ferrazzi E. Delivery in pregnant women infected with SARS-CoV-2: A fast review. Int J Gynecol Obstet. 2020 [ahead of print] https://doi.org/10.1002/ijgo.13166 